\title{
Technical note: Test of a low-cost and animal-friendly system for measuring methane emissions from dairy cows
}

\author{
A. L. F. Hellwing, ${ }^{1}$ P. Lund, M. R. Weisbjerg, M. Brask, and T. Hvelplund \\ Department of Animal Science, Aarhus University, AU Foulum, PO Box 50, DK-8830 Tjele, Denmark
}

\section{ABSTRACT}

Methane is a greenhouse gas with a significant anthropogenic contribution from cattle production. A demand exists for techniques that facilitate evaluation of mitigation strategies for dairy cows. Therefore, a low-cost system facilitating the highest possible animal welfare was constructed and validated. The system uses the same principles as systems for open-circuit indirect calorimetry, but to lower the costs, the chamber construction and air-conditioning system were simpler than described for other open-circuit systems. To secure the highest possible animal welfare, the system is located in the cow's daily environment. The system consists of 4 transparent polycarbonate chambers placed in a square so that the cows are facing each other. The chamber dimensions are 183 (width), 382 (length), and $245 \mathrm{~cm}$ (height) with a volume of $17 \mathrm{~m}^{3}$. Flow and concentrations of $\mathrm{O}_{2}, \mathrm{CO}_{2}, \mathrm{CH}_{4}$, and $\mathrm{H}_{2}$ are measured continuously in the outlet. Flow is measured with a mass flow meter, $\mathrm{O}_{2}$ with a paramagnetic sensor, $\mathrm{CO}_{2}$ and $\mathrm{CH}_{4}$ with infrared sensors, and $\mathrm{H}_{2}$ with an electrochemical sensor. Chamber inlet is placed in the barn and background concentrations may differ between chambers, but delta values between background and outlet concentrations for all chambers were within instrument tolerance. Average recovery rates of $\mathrm{CO}_{2}$ and $\mathrm{CH}_{4}$ were (mean $\pm \mathrm{SD}$ ) $101 \pm 4$ and $99 \pm 7 \%$, respectively. This is within the expected tolerance of the whole system (gas sensors and flow meters). Feed dry matter intakes were not affected by confining the animals in chambers, as dry matter intake before and during chamber stay were similar. It was concluded that the system delivers reliable values, and the transparent construction in combination with the location in the barn environment prevent negative impact on animal welfare and, thereby, data quality.

Key words: methane, dairy cow, chamber

Received March 5, 2012

Accepted June 13, 2012.

${ }^{1}$ Corresponding author: AnneLouise.Hellwing@agrsci.dk

\section{Technical Note}

Methane is a greenhouse gas with a global warming potential of 25 times that of carbon dioxide (IPCC, 2007). Enteric methane from lactating dairy cows accounted for $27 \%$ of all emitted methane in Denmark in 2008 (Nielsen et al., 2010). All countries have to deal with mitigation strategies, and numerous research institutes are now building chambers for measuring methane emissions from, for example, dairy cows. However, building traditional chambers for open-circuit indirect calorimetry is expensive because of the demand for sealing, climate regulation, and internal circulation of air. Furthermore, the chambers have traditionally been built in stainless steel with only small windows, which may restrict normal social behavior (Johnson et al., 1994). We built a system following the same principle, but with 4 chambers made of transparent polycarbonate with air inlets at the floor level of the chamber and no internal circulation. The chambers are placed in the cow barn to reduce the effect of environmental change in connection with measurements. However, this approach differs from traditional systems with respect to, for example, homogeneity of inlet air. We hypothesized that the recovery of added gas would be $100 \%$, that DMI during chamber confinement would be similar to DMI when housed outside the chamber, that the background level in the different chambers would be similar for the 4 chambers, and that the contribution of methane from feces in the chambers could be ignored. The aims of the study were (1) to describe the system and to discuss the usability of the system, (2) to test the recovery of an amount of gas added to the chamber equivalent to the expected emission level for cattle, (3) to compare DMI before and during chamber stay, (4) to study any differences in background level of gasses between chambers, (5) to compare the air composition at different locations in the chamber with measured levels in outlet air from the whole chamber to study whether outlet air represented average chamber concentrations, and (6) to study the amounts of $\mathrm{CO}_{2}$ and $\mathrm{CH}_{4}$ emitted from the manure in the chamber.

The use of the chambers complied with the guidelines of the Danish Ministry of Justice (Copenhagen, 


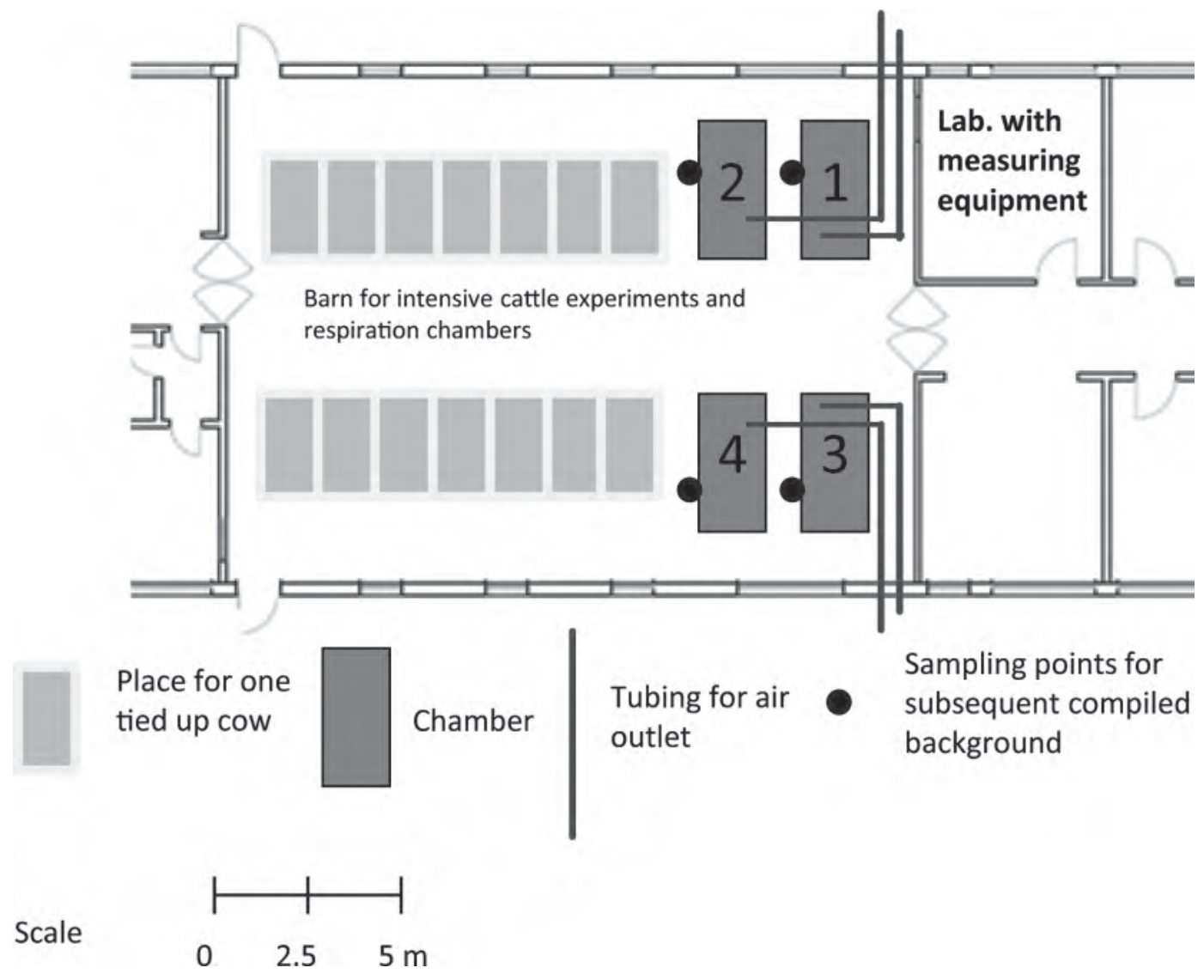

Figure 1. Drawing of the barn with chambers.

Denmark) with respect to animal experimentation and care of animals under study. The open-circuit indirect calorimetry system consisted of 4 chambers that were placed in a traditional experimental tie-stall barn with 14 beds (Figure 1). The chambers were placed in a square where all cows faced the middle and, therefore, had visual contact (Figure 2A). Each chamber was built around a platform designed for housing cattle during intensive metabolic studies.

The lying area was $170 \mathrm{~cm}$ long and $165 \mathrm{~cm}$ wide and was covered with a rubber mat. Behind the platform was a $68-\mathrm{cm}$ slurry grate (Figure 2B), and underneath the slurry grate, a 4 -wheel cart was placed for feces and urine collection (Figure 2C). The feeding tray was placed on a 4 -wheeled cart with a scale for continuous online registration of feed intake (Bjerringbro Vægte, Bjerringbro, Denmark). The feeding tray was designed to reduce feed loss during eating and to give the possibility for both TMR and individual feeding of concentrate (Figure 2D). The feeding tray measured $144 \times 43 \mathrm{~cm}$. The feeding tray could contain half of the daily ration for a dairy cow. If the concentrate was given separately, an extra tray was mounted inside the feeding tray. The water bowl was placed in the platform area on the right side of the cow's head. The water intake was registered online with a Sensus HRI meter (Brødrene Dahl A/S, Brøndby, Denmark).

The construction of the chambers was based on frames of $40 \times 40-\mathrm{mm}$ steel tubes built around the platform. The outside dimensions of the chambers were 183 (width), 382 (length), and $245 \mathrm{~cm}$ (height), resulting in a chamber volume of $17 \mathrm{~m}^{3}$.

Doors with a height of $177 \mathrm{~cm}$ were placed in the rear end and were used when cows were moved and during milking and cleaning. Doors with a height of $122 \mathrm{~cm}$ in the front were used for feeding. The edges on the front and rear doors were covered with draft strips to prevent air leakage. Each chamber was built in 2 separate parts, which made the transport easier. The metal frame was painted before polycarbonate plates were mounted. The transparent polycarbonate plates were $6-\mathrm{mm}$ thick and were fixed with glue and stopper pins on the steel frame. The edges of the 2 sections were covered with draft strips and subsequently bolted together. The chambers were fixed to the floor, and the gap between the floor and chamber was sealed in the 

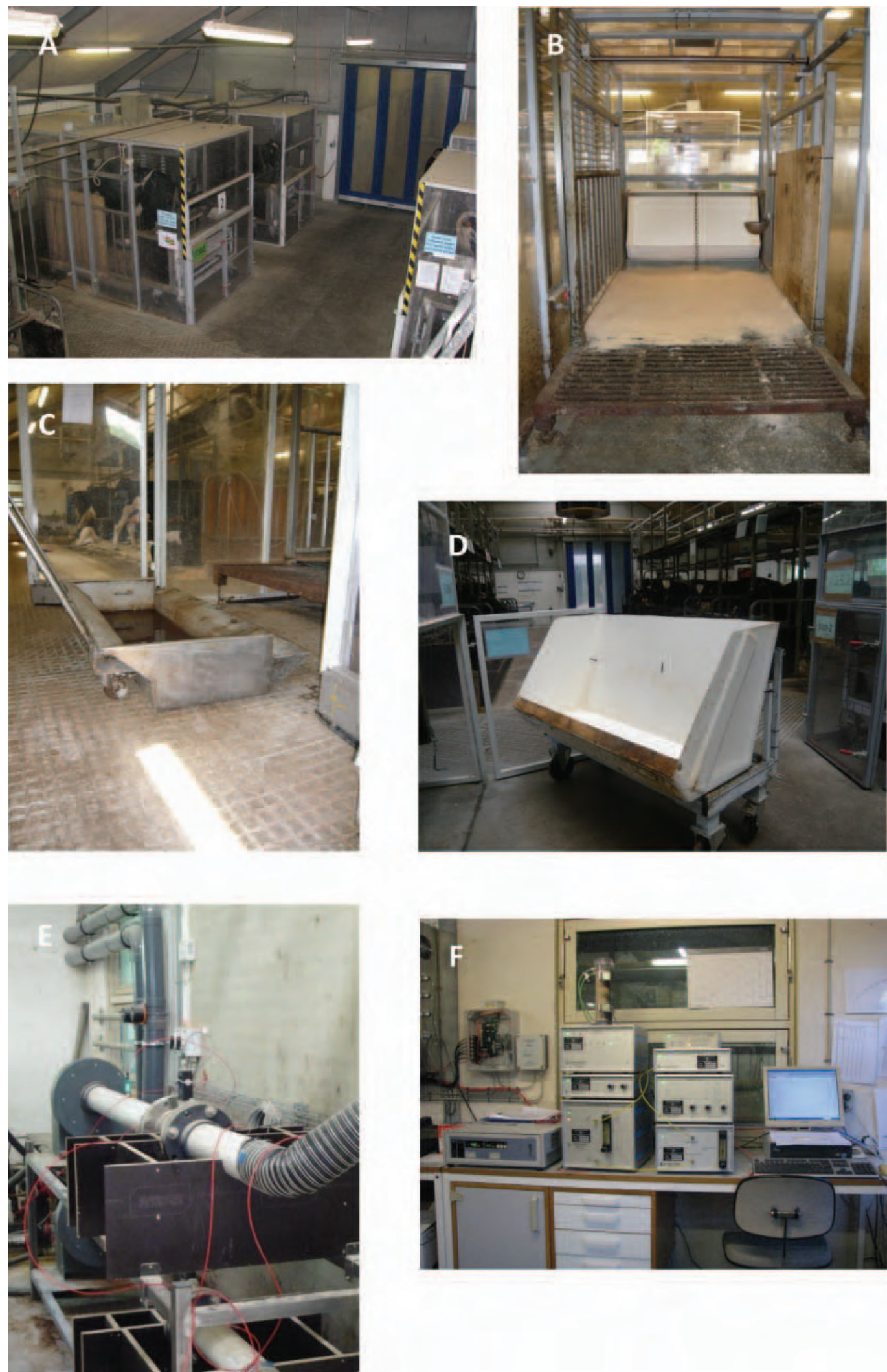

Figure 2. (A) Overview of the chambers in the barn; (B) chamber and platform from behind; (C) cart for feces and urine; (D) cart with feeding tray; (E) flow system with flow meter in the front and blower in the back; $(\mathrm{F})$ instruments used to control and measure $\mathrm{O}_{2}, \mathrm{CO}_{2}$, $\mathrm{CH}_{4}$, and $\mathrm{H}_{2}$. Color version available in the online PDF. 
front part. In the rear third of the chamber, the gap was not fully sealed to allow air inlet. Vacuum and milk pipe lines led through the chamber wall to facilitate milking.

The air flow through the chambers was controlled by a Dayton 2C820 high-pressure direct drive radial blade fan with a $0.9 \mathrm{KW}$ motor (VEM Motors $\mathrm{GmbH}$, Wernigerode, Germany) regulated by an Altivar 31 motor controller (Schneider Electric SA, Rueil Malmaison, France). Each motor and thereby the ventilation rate for each chamber could be regulated separately. The ventilation rate was set to maintain the concentration of $\mathrm{CO}_{2}$ between 5,000 and $6,000 \mu \mathrm{L} / \mathrm{Lfor}$ each chamber. Actual air flow was measured for each chamber by an HFM-200 mass flow meter with a laminar flow element from Teledyne-Hastings Instruments (Hampton, VA). The flow meter could measure flows up to $3,000 \mathrm{~L} / \mathrm{min}$ (LPM). The laminar flow element had a diameter of 10 $\mathrm{cm}$. The accuracy of the flow meter was $1 \%$ of full scale, and the repeatability was $0.05 \%$ of full scale. The flow meter was calibrated with air and had an integrated thermometer and manometer that correct the flow to standard temperature and pressure $\left[0^{\circ} \mathrm{C}(273.15 \mathrm{~K})\right.$ and $101.325 \mathrm{kPa}]$.

The flow meter was mounted in level, and to ensure a laminar flow, a straight polyvinyl chloride (PVC) tube was mounted $60 \mathrm{~cm}$ before and $120 \mathrm{~cm}$ after the flow meter (Figure 2E). A $31 \times 31-\mathrm{cm}$ filter box was mounted in the top of each chamber at the outlet, centered between the 2 sides and $150 \mathrm{~cm}$ behind the front end, to ensure that air was dust free. A metal grating separated the filter box from the chamber. The air from the chambers was drawn through 4 filters. The first filter was a reticulated washable foam slab. The following 3 filters were panel filters. The filters were controlled regularly and changed if needed. The filter box and subsequent PVC tube for outlet air were connected by a flexible hose. The filter system is under reconstruction due to possible risk of dust entering the flow meters.

Temperature and humidity were registered every fifth minute in each chamber during the whole experiment to monitor the climate condition for each chamber (Veng System A/S, Roslev, Denmark). To reduce humidity and avoid heat stress in the chambers, 2 refrigerating plants, 1 per 2 chambers (Ascon International, Derby, UK), dehumidified the air in the chambers by circulating cold water $\left(-1\right.$ to $\left.2^{\circ} \mathrm{C}\right)$ through pipes with a total surface area of $4.3 \mathrm{~m}^{2}$ per chamber. The temperature of the chambers could not be regulated, but the barn had a heating system, and the minimum temperature was set to $14^{\circ} \mathrm{C}$.

The system had 5 measuring channels. Four channels were used for sampling air from the chambers and 1 for the background. The whole measuring system, including the flow meters, control system for motors, and data handling, was delivered by Columbus Instruments (Columbus, OH). The measuring system consisted of a 5-channel multiport switch, a system sample pump, an $\mathrm{H}_{2}$ sensor, a sample drier, an $\mathrm{O}_{2}$ sensor, a $\mathrm{CO}_{2}$ sensor, and a $\mathrm{CH}_{4}$ sensor (Figure $2 \mathrm{~F}$ ).

Chamber air outflow was sampled in the middle of the PVC tube between the flow meter and the blower. The sample for background concentration of gases was compiled from sampling at 4 different locations (i.e., near the inlet of each chamber; Figure 1). Before the air enters the measuring system, ammonia and dust were removed by filters (Balston products from Parker Hannifin Corp., Haverhill, MA). The flow in the measuring system was regulated by the system sample pump and was set to 0.5 LPM. Atmospheric air was dried in 2 bottles filled with molecular sieves $(0.4 \mathrm{~nm}$, beads, with indicator; Merck KGaA, Darmstadt, Germany) and is pumped through the outer tube with a flow of 2 LPM, thereby drying the air sample in the inner tube made of Nafion.

Hydrogen was measured by an electrochemical sensor just before the air was dried. After drying, $\mathrm{O}_{2}$ was measured with a paramagnetic sensor and $\mathrm{CO}_{2}$ and $\mathrm{CH}_{4}$ with infrared sensors (see Table 1 for details of sensors). Data from the flow meters and sensors were recorded on a computer through a bus serial interface.

All 4 sensors were calibrated before the start of a measurement and every second day during measurements in connection with feeding and milking routines. The zero point was calibrated with pure nitrogen, and the span point of each sensor was calibrated using a calibration gas with a concentration of $20.5 \mathrm{cL} / \mathrm{L}$ of $\mathrm{O}_{2}$, $0.5 \mathrm{cL} / \mathrm{L}$ of $\mathrm{CO}_{2}, 800 \mu \mathrm{L} / \mathrm{L}$ of $\mathrm{CH}_{4}$, and $150 \mu \mathrm{L} / \mathrm{L}$ of $\mathrm{H}_{2}$ in nitrogen (AGA, Copenhagen, Denmark). The gas

Table 1. List of sensors, measuring range, calibration, and tolerance of sensors

\begin{tabular}{lllll}
\hline Sensor & Principle & Range & $\begin{array}{l}\text { Zero/span } \\
\text { calibration }\end{array}$ & Tolerance \\
\hline $\mathrm{H}_{2}(\mu \mathrm{L} / \mathrm{L})$ & Chemical & $0-2,000$ & $0 / 150$ & 0.3 \\
$\mathrm{CO}_{2}(\mu \mathrm{L} / \mathrm{L})$ & Infrared & $0-10,000$ & $0 / 5,000$ & $<20$ \\
$\mathrm{O}_{2}(\mathrm{cL} / \mathrm{L})$ & Paramagnetic & $0-100$, but most accurate between 20 and 21 & $0 / 20.50$ & 0.01 between 20 and 21 \\
$\mathrm{CH}_{4}(\mu \mathrm{L} / \mathrm{L})$ & Infrared & $0-1,000$ & $0 / 800$ & $\pm 1.5 \%$ of full scale \\
\hline
\end{tabular}


composition was guaranteed within a relative tolerance at $0.1 \%$ for $\mathrm{O}_{2}$ and $1 \%$ for $\mathrm{CO}_{2}, \mathrm{CH}_{4}$, and $\mathrm{H}_{2}$.

The system measured the 5 channels sequentially; as default, the system measured the background concentration followed by chambers $1,2,3$, and 4 and then the background again followed by the chambers, and so on. If needed, chambers could be switched off, and also the number of measurements between background measurements could be changed. To avoid carryover effects, an initial 2-min purge time preceded the subsequent 30 -s measuring time. Background and chambers were, therefore, measured every $12.5 \mathrm{~min}$, and during $24 \mathrm{~h}$ of measurements, this gave 115 data points per chamber.

Animal safety was a prerequisite. In case of $\mathrm{CO}_{2}$ levels exceeding $9,000 \mu \mathrm{L} / \mathrm{L}$, a power cut, or temperature exceeding the default threshold, a GSM modem with external power supply sent an alarm to a cell phone. This was to secure animal safety and data quality, as $\mathrm{CO}_{2}$ levels above $10,000 \mu \mathrm{L} / \mathrm{Lcould}$ not be measured. The $\mathrm{CO}_{2}$ and temperature sensors used in the alarm system were independent of the rest of the measuring system, and data were logged continuously. The whole alarm system was delivered by Veng System A/S.

Emissions of $\mathrm{CH}_{4}, \mathrm{CO}_{2}, \mathrm{H}_{2}$, and consumption of $\mathrm{O}_{2}$ were calculated from the flow of outgoing air in standard temperature and pressure and the concentration of gasses in barn air (background) and in outgoing air from the chamber. Data points obtained when the chambers were open were deleted and were assumed to represent the average emission or consumption of the data set. Per milking and feeding, normally 2 to 3 data points were omitted, giving a data gap corresponding to $1 \mathrm{~h} / \mathrm{d}$ with 2 daily milkings/feedings. Feed was fed just before chambers were closed to ensure potential peaks in emissions after feeding was recorded.

The daily emission was calculated according to Brown et al. (1984), including correction for the difference in volume of ingoing and outgoing gases, and correction for changes in the chamber concentration of gas. This correction was based on the assumption that outlet concentrations at the onset and end were equivalent to concurrent mean chamber concentrations.

The measuring period was either 2 or $4 \mathrm{~d}$. Animals stayed in the same chamber when only measured for 2 d. If measured for $4 \mathrm{~d}$, the animals changed chambers in a diagonal way to balance out any eventual deviation in the background (barn air). Chamber opening was restricted to feeding and milking times, normally twice daily. Opening and closing times of the chambers were recorded.

The total price of the system was approximately $\$ 300,000$ including $\$ 140,000$ for sensors and flow meters, $\$ 70,000$ for chambers, $\$ 30,000$ for air conditioning,
$\$ 20,000$ for the alarm system, and $\$ 40,000$ for test gases, online feeding trays, manure carts, and other items.

The following tests were conducted to document the accuracy of the system: recovery, DMI, background variation, concentration gradients, and emissions from manure. For recovery, tubes from gas cylinders $\left(\mathrm{CO}_{2}\right.$ or $\mathrm{CH}_{4}$, or both) with a known weight were put into the chamber; if more than 1 chamber was tested at the same time, separate gas cylinders were used for each. The measurements were started and the gas cylinders were opened. The weight decrease of the gas cylinder was at least $200 \mathrm{~g}$ to minimize measuring errors. After the cylinders were closed, measurements continued for at least $1 \mathrm{~h}$ to return to barn level. The measured accumulated gas was compared with the measured input. Tests with $\mathrm{CO}_{2}$ and $\mathrm{CH}_{4}$ took approximately 4 and 24 $\mathrm{h}$, respectively, when flow rate of exhaust gas was 1,000 LPM.

The DMI $4 \mathrm{~d}$ before and during chamber confinement was calculated for experiments from May 2010 until July 2011 with dairy cows, bulls and heifers. One experiment was omitted due to recruitment of cows directly from loose housing to chambers.

As estimates of background, the concentrations of $\mathrm{O}_{2}$, $\mathrm{CO}_{2}$, and $\mathrm{CH}_{4}$ in the outlets from the 4 chambers without cows and in the compiled background sample were measured for a 48 - $\mathrm{h}$ period at 3 dates (March, May, and June 2010). Nine cows were in the barn during this period. Mean delta values were calculated for each chamber as the difference between the concentration in outlet air and in the compiled background sample. The mean delta values were analyzed in PROC GLM with chamber and period as fixed effects.

A dry cow was placed in the chamber to study the concentration gradients. A sampling line was placed inside the chamber in the top, middle, and bottom in a vertical direction and in the front, middle, and back in a horizontal direction for a total of 9 measuring points. The same chamber was used for all of the measurements. The differences in the $\mathrm{CH}_{4}$ concentration of samples taken within the chamber and from the outlet were calculated. Mean values and standard deviation were calculated by PROC MEANS in SAS (SAS Institute Inc., Cary, NC). The mean value was tested for deviation from zero by $t$-test.

Carbon dioxide and $\mathrm{CH}_{4}$ emissions were measured in chambers with feces and urine produced by lactating cows during the last $14 \mathrm{~h}$ of an experiment. Hourly emission rates and standard error of means for $\mathrm{CO}_{2}$ and $\mathrm{CH}_{4}$ emissions were calculated.

The principle behind systems for open-circuit indirect calorimetry is simple. But construction of a system without gas leaks, with comfortable climate in the 


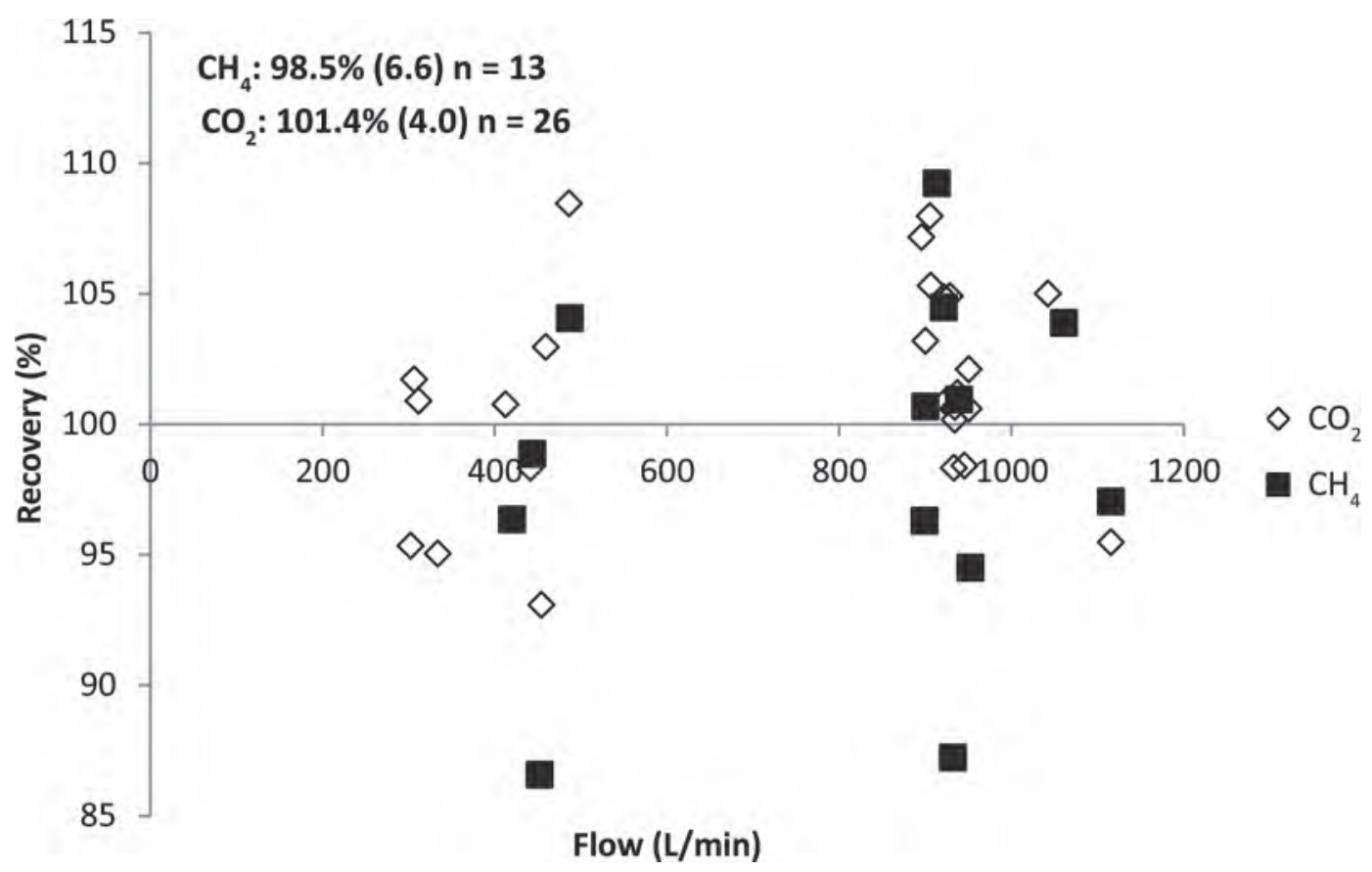

Figure 3. Recovery test of $\mathrm{CH}_{4}$ and $\mathrm{CO}_{2}$ at different flow rates.

chambers for the animal, and representative sampling can be difficult. During the last century, many different systems have been constructed with the main focus on energy metabolism (Derno et al., 2009). During the last decade, the focus has changed toward systems constructed with the main purpose of measuring $\mathrm{CH}_{4}$ (Klein and Wright, 2006). These systems often have, as the present system, a simpler construction and are noninsulated, without airlock and without internal air circulation (Pinares and Waghorn, 2012).

The obtained recoveries of $\mathrm{CO}_{2}$ and $\mathrm{CH}_{4}$ are given in Figure 3. The average recoveries for $\mathrm{CO}_{2}$ and $\mathrm{CH}_{4}$ were $($ mean $\pm \mathrm{SD}) 101.4 \pm 4.0$ and $98.5 \pm 6.6 \%$, respectively. The variation in the recovery of $\mathrm{CO}_{2}$ was less than for $\mathrm{CH}_{4}$, as the amount of gas used in recovery tests were higher for $\mathrm{CO}_{2}$ than for $\mathrm{CH}_{4}$. Therefore, the random error due to weighing of the gas cylinder was less for $\mathrm{CO}_{2}$. As an example of a similar low-cost system, recovery of $\mathrm{CH}_{4}$ from a polyethylene tunnel used for grazing animals amounted to 89 to $97 \%$ in the experiment of Murray et al. (1999) and to 82 to $118 \%$ in the experiment of Lockyer and Jarvis (1995). Carbon dioxide deviations of $\pm 10 \%$ have been reported even in systems built according to normal standards for systems for indirect calorimetry (Miller and Koes, 1988). However, studies with much higher precision also exist, reporting deviations less than $\pm 2 \%$ (Schoffelen et al., 1997). The accuracy of the recovery will depend on instrument tolerance (flow meter, gas sensor, and scale). In our system, the most critical factor was the flow meter. The accuracy of the flow meter is expressed as $1 \%$ of full scale $(3,000 \mathrm{LPM})$, and at 1,000 LPM the flow can, therefore, deviate $3 \%$, and at 300 LPM deviate $10 \%$. The average recoveries for both $\mathrm{CO}_{2}$ and $\mathrm{CH}_{4}$ were within an acceptable limit in our system. Therefore, no correction of the gas recovery was conducted.

Unchanged ad libitum DMI in the chamber period compared with the period before chamber confinement is believed to indicate that cows are unstressed. However, DMI before and during chamber stay is seldom published. In a study by Beauchemin and McGinn (2006) on heifers, the DMI was between 6.1 and 10.1\% lower during stay in a closed chamber than outside. In our study, DMI before and during $\mathrm{CH}_{4}$ measurements were similar, as shown in Figure 4. Based on a regression analysis, the DMI $(\mathrm{kg} / \mathrm{d})$ in the chamber regressed on intake before chamber gave a slope of 1.03 , an intercept at -0.34 , and a coefficient of determination of 0.95. This indicates that transparent chambers placed in the cows' daily environment and visual contact between cows resulted in DMI similar to the period before chamber confinement. Constant daily DMI is essential, as daily DMI is the main driver for methane production (Ellis et al., 2007).

The problem with decreased DMI for loose-housed cattle can be solved by housing the animal in a tiestall for a few days before the start of the experiment. Experiments with bulls and heifers were conducted on 


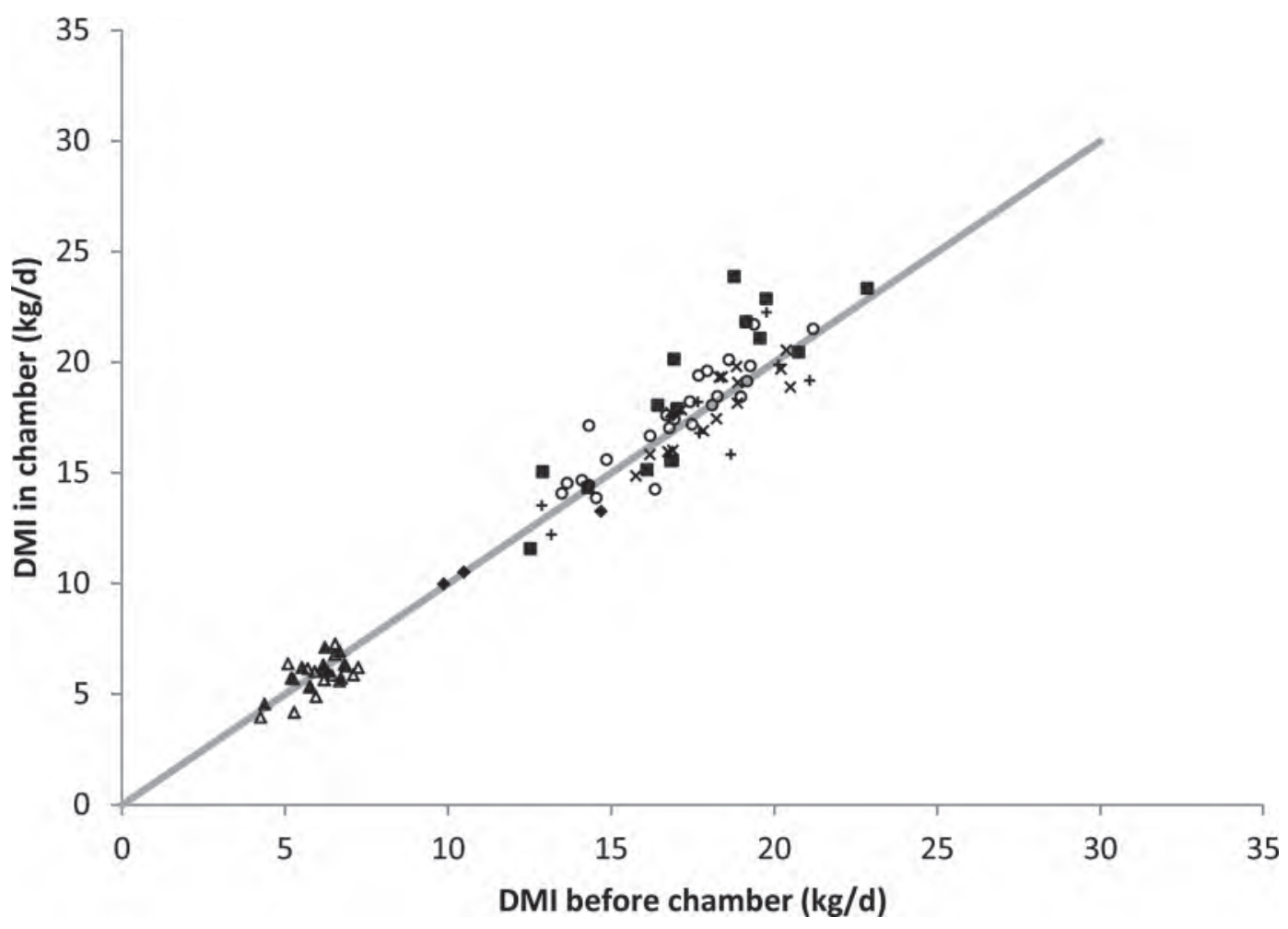

Figure 4. Correlation between DMI 4 d before animals entered the chamber and during confinement. Diamonds are from 1 experiment with dry cows. Triangles are from 2 experiments with 300-kg heifers (open) and bulls (closed). Squares, circles, crosses, and pluses are from 4 studies with lactating dairy cows. The line indicates $\mathrm{y}=\mathrm{x}$.

loose-housed animals that were tied up for 3 to $7 \mathrm{~d}$ before $\mathrm{CH}_{4}$ measurements were conducted (Figure 4).

No differences between chambers were observed in the background level $(P>0.4$; Table 2$)$. The average differences between barn background and chamber concentrations were $-32 \mu \mathrm{L} / \mathrm{L}$ for $\mathrm{O}_{2}, 3.9 \mu \mathrm{L} / \mathrm{L}$ for $\mathrm{CO}_{2}$, and $0.2 \mu \mathrm{L} / \mathrm{L}$ for $\mathrm{CH}_{4}$. These deviations are insignificant when compared with the background level of $20.7 \mathrm{cL} / \mathrm{L} \mathrm{O}_{2}, 500$ to $1,000 \mu \mathrm{L} / \mathrm{L}$ for $\mathrm{CO}_{2}$, and 20 to $40 \mu \mathrm{L} / \mathrm{L}$ for $\mathrm{CH}_{4}$. For all 3 gases, these deviations are below the tolerance level of the individual instruments (Table 1). If the air flow is 1,000 LPM, the theoretical error averages $0.3 \mathrm{~L}$ of $\mathrm{CH}_{4}$ per day (less than $0.1 \%$ ), assuming that a dairy cow produces $500 \mathrm{~L}$ of $\mathrm{CH}_{4} / \mathrm{d}$. The low delta values and the absence of an effect of chamber show that the difference in background in this barn is negligible when related to the tolerance of the instruments and to the enteric $\mathrm{CH}_{4}$ production. To further reduce the risk of systematic errors due to possible chamber differences, cows normally switched chambers diagonally halfway through a $96-\mathrm{h}$ measuring period.

The concentration of $\mathrm{CH}_{4}$ differed between measuring points (Figure 5). Only in the middle back $(\sim 1$ $\mathrm{m}$ from the chamber bottom) were concentrations of $\mathrm{CH}_{4}$ in the chamber similar to outlet values, whereas concentrations of $\mathrm{CH}_{4}$ measured at the other measuring points differed significantly from the outlet. The measured concentration differences reflected the emission points and the air movements within the chamber so that positive values were found in the front near the head of the cow, and the negative values were found in the bottom where the main part of the fresh air was

Table 2. Delta values between the gas concentration in the compiled background sample and in each chamber for $\mathrm{O}_{2}, \mathrm{CO}_{2}$, and $\mathrm{CH}_{4}$

\begin{tabular}{|c|c|c|c|c|c|c|c|}
\hline \multirow{2}{*}{$\begin{array}{l}\text { Delta } \\
(\mu \mathrm{L} / \mathrm{L})\end{array}$} & \multicolumn{4}{|c|}{ Chamber } & \multirow[b]{2}{*}{ SEM } & \multicolumn{2}{|c|}{$P$-value } \\
\hline & 1 & 2 & 3 & 4 & & Period & Chamber \\
\hline $\mathrm{O}_{2}$ & -54 & -13 & -31 & -30 & 20.5 & 0.01 & 0.46 \\
\hline $\mathrm{CO}_{2}$ & 3.9 & 6.9 & 0.9 & 3.8 & 9.9 & 0.17 & 0.97 \\
\hline $\mathrm{CH}_{4}$ & -0.1 & 0.3 & 0.1 & 0.6 & 1.12 & 0.46 & 0.96 \\
\hline
\end{tabular}




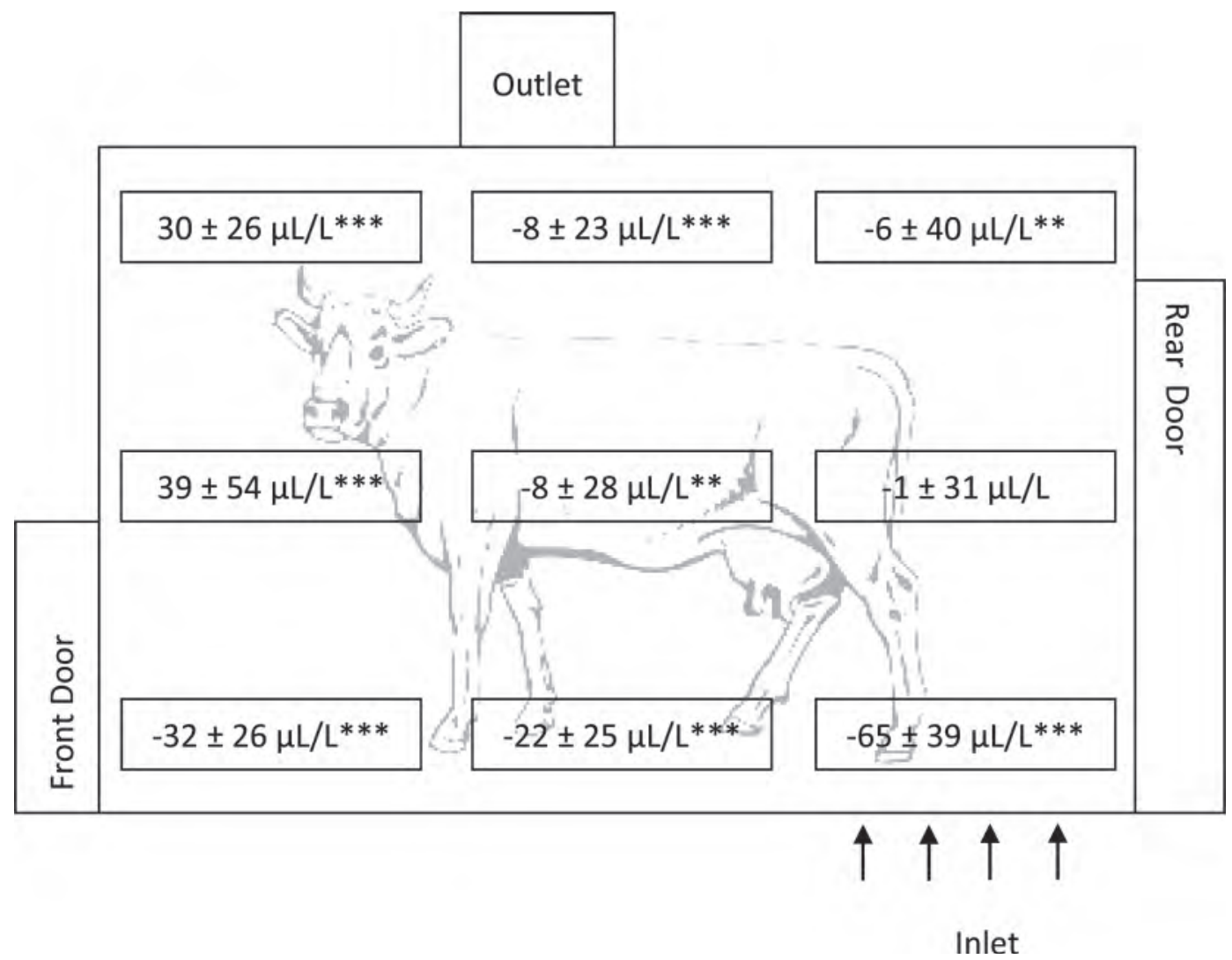

Figure 5. Differences between chamber and outlet concentrations of $\mathrm{CH}_{4}$ at 9 different places in the chamber covering both horizontal and vertical directions. The values are given in microliters per liter with standard error, and stars indicate that means differ significantly from zero. *** $P<0.001 ; * * P<0.01$.

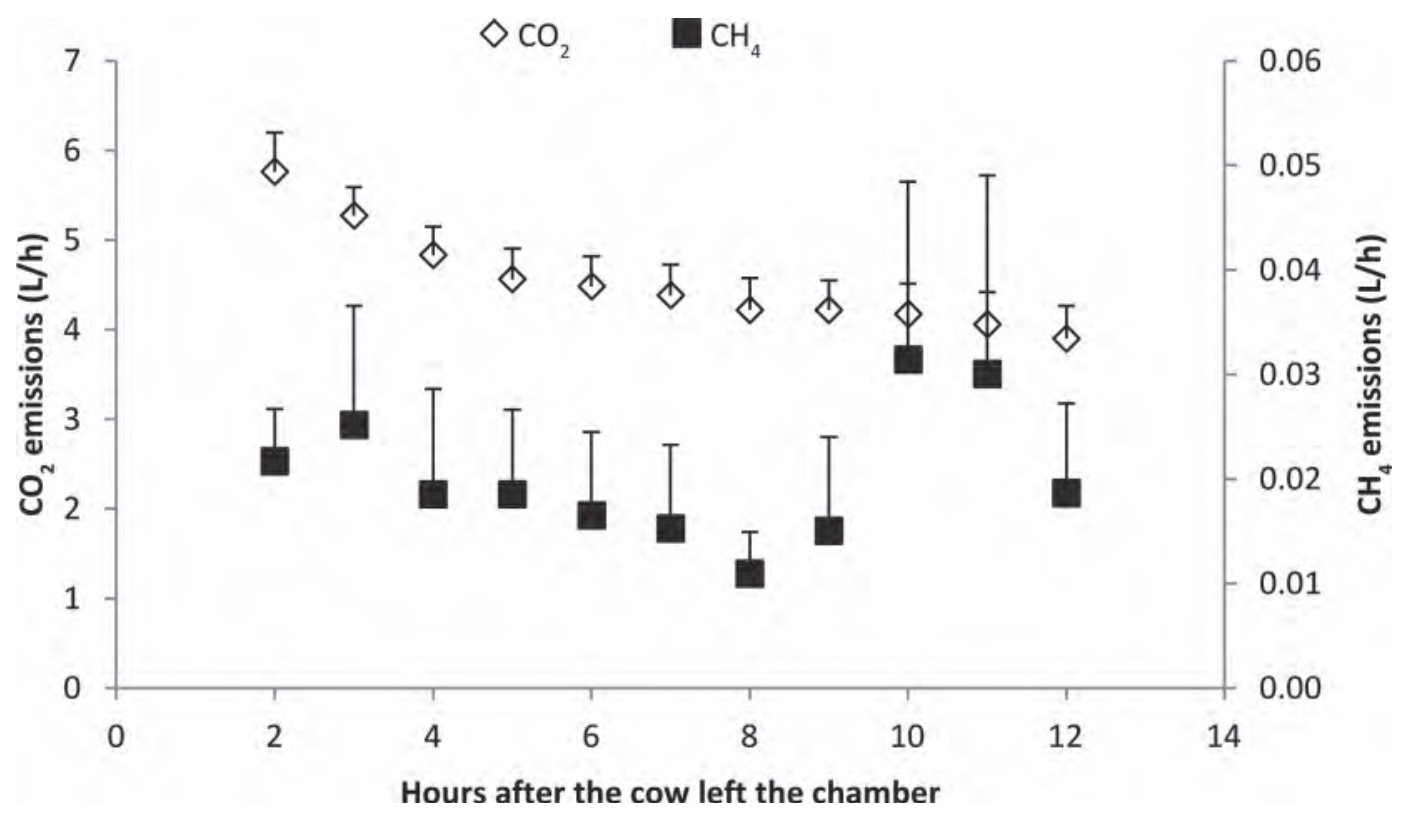

Figure 6. Emission of $\mathrm{CO}_{2}$ and $\mathrm{CH}_{4}$ from manure left after an animal experiment. 
expected to enter the chamber. This clearly shows that air inside the chamber, as expected, was not homogeneously mixed due to the lack of internal circulation. However, when balance was established in the chamber, the measured outlet values were representative for the system. It can be compared with a system that has a unidirectional flow with a concentration gradient in the flow direction. However, an insignificant error can arise due to opening of the chambers for feeding and milking. The response time is exponential (Brown et al., 1984) and for our system $50 \%$ of a change was received after 12 min when the flow was 1,000 LPM. However, correction for this was included in our calculation, as described by Brown et al. (1984).

The hourly $\mathrm{CH}_{4}$ emission rate from manure accumulated over $14 \mathrm{~h}$ was $0.02 \mathrm{~L} / \mathrm{h}$ for the first $12 \mathrm{~h}$ after the end of the animal experiment (Figure 6), showing that emission of methane from manure was negligible (i.e., only $0.1 \%$, assuming that a cow produces $500 \mathrm{~L}$ of $\mathrm{CH}_{4}$ per day). The $\mathrm{CO}_{2}$ emission was $5.8 \mathrm{~L} / \mathrm{h}$ in the first hours and decreased to $3.9 \mathrm{~L} / \mathrm{h}$ after $12 \mathrm{~h}$ (Figure 6 ), on average $4.5 \mathrm{~L} / \mathrm{h}$, which is equivalent to $2 \%$ of the total production, assuming a daily production of $5,500 \mathrm{~L}$ of $\mathrm{CO}_{2}$. It can be concluded that $\mathrm{CH}_{4}$ emission from manure does not contribute significantly to the measured emission of enteric $\mathrm{CH}_{4}$ in the system.

The described system measures reliable values of $\mathrm{CH}_{4}$ production in dairy cows, even though inlet air is from the barn and internal circulation normally characterizing systems for open-circuit indirect calorimetry is lacking. The use of transparent polycarbonate plates for chamber walls and roof and the location in the barn seems to ensure natural behavior and normal feed intake levels. The system has now been running for $2 \mathrm{yr}$ and has produced reliable results without any major problems.

\section{ACKNOWLEDGMENTS}

We gratefully acknowledge the Danish Ministry of Food, Agriculture and Fisheries (Copenhagen, Den- mark), Mælkeafgiftsfonden (Aarhus, Denmark), and Aarhus University (Tjele, Denmark) for funding.

\section{REFERENCES}

Beauchemin, K. A., and S. M. McGinn. 2006. Methane emissions from beef cattle: Effects of fumaric acid, essential oil, and canola oil. J. Anim. Sci. 84:1489-1496.

Brown, D., T. J. Cole, M. J. Dauncey, R. W. Marrs, and P. R. Murgatroyd. 1984. Analysis of gaseous exchange in open-circuit indirect calorimetry. Med. Biol. Eng. Comput. 22:333-338.

Derno, M., H. G. Elsner, E. A. Paetow, H. Scholze, and M. Schweigel. 2009. Technical note: A new facility for continuous respiration measurements in lactating cows. J. Dairy Sci. 92:2804-2808.

Ellis, J. L., E. Kebreab, N. E. Odongo, B. W. McBride, E. K. Okine, and J. France. 2007. Prediction of methane production from dairy and beef cattle. J. Dairy Sci. 90:3456-3466.

IPCC (Intergovernmental Panel on Climate Change). 2007. Climate change 2007: The physical science basis. Contribution of Working Group I to the Fourth Assessment Report of the IPCC. Cambridge University Press, Cambridge, UK, and New York, NY.

Johnson, K., M. Huyler, H. Westberg, B. Lamb, and P. Zimmerman. 1994. Measurement of methane emissions from ruminant livestock using a $\mathrm{SF}_{6}$ tracer technique. Environ. Sci. Technol. 28:359-362.

Klein, L., and A. D. G. Wright. 2006. Construction and operation of open-circuit methane chambers for small ruminants. Aust. J. Exp. Agric. 46:1257-1262.

Lockyer, D. R., and S. C. Jarvis. 1995. The measurement of methane losses from grazing animals. Environ. Pollut. 90:383-390.

Miller, W. H., and R. M. Koes. 1988. Construction and operation of an open-circuit indirect calorimetry system for small ruminants. J. Anim. Sci. 66:1042-1047.

Murray, P. J., A. Moss, D. R. Lockyer, and S. C. Jarvis. 1999. A comparison of systems for measuring methane emissions from sheep. J. Agric. Sci. 133:439-444.

Nielsen, O.-K., M. Winther, M. H. Mikkelsen, S. Gyldenkærne, E. Lyck, M. Plejdrup, L. Hoffmann, M. Thomsen, K. Hjelgaard, and P. Fauser. 2010. Projection of greenhouse gas emissions 2009 to 2030. NERI Technical Report No. 793. National Environmental Research Institute, Aarhus University, Roskilde, Denmark.

Pinares, C., and G. Waghorn. 2012. Technical manual on respiration chamber designs. Ministry of Agriculture and Forest, Wellington, New Zealand. Accessed May 22, 2012. http://www.globalresearchalliance.org/app/uploads/2012/03/GRA-MAN-FacilityBestPract-2012-FINAL.pdf.

Schoffelen, P. F. M., K. R. Westerterp, W. H. M. Saris, and F. Ten Hoor. 1997. A dual-respiration chamber system with automated calibration. J. Appl. Physiol. 83:2064-2072. 